\title{
Lewis Carroll's regress and the presuppositional structure of arguments
}

\section{Carlotta Pavese ${ }^{1}$ (D)}

Accepted: 2 December 2020

(C) The Author(s), under exclusive licence to Springer Nature B.V. part of Springer Nature 2021

\section{Abstract}

This essay develops and defends a diagnosis of (Carroll in Mind 4(14):278-80, 1895)'s regress of the premises according to which the moral of the regress is that arguments are constitutively presuppositional. It is argued that this diagnosis allows to vindicate the key insights of the rule-following account of the regress, while overcoming the main difficulties that the rule-following account faces.

Keywords Arguments · Presupposition · Regress

\section{Introduction}

Carroll (1895)'s famous regress of the premises arises in the course of an argument between Achilles and Tortoise that has the following structure. Suppose $p$ and if $p$ then $q$. From that, Achilles would really want to conclude that $q$. Tortoise would not allow it: $q$ can be concluded-she objects-only if it is true that if $p$ and if $p$ then $q$ then $q$. Hence, Achilles is led to suppose, in addition, that it is true that if $p$ and if $p$ then $q$ then $q$. From that together with the earlier premises, Achilles would want to conclude that $q$. Tortoise would not allow it: it can be concluded that $q$-she objects-only if it is true that if $p$ and if $p$ then $q$ then $q$. No provision of further premises will convince Tortoise to accept the conclusion. An infinite regress ensues.

I am grateful to Harold Hodes, Arc Kocurek, and Tim Williamson for helpful discussion about these topics, as well as to two anonymous reviewers for comments that have greatly contributed to improving this essay.

Carlotta Pavese

cp645@cornell.edu

1 Sage School of Philosophy, Cornell University, Ithaca, NY, USA 
In the light of this regress, we are led to conclude that giving (or making) an argument by modus ponens is impossible. But giving (or making) an argument by modus ponens is, of course, possible. ${ }^{1}$ Hence, the paradox:

Paradox How it is possible to give (or make) an argument by a logical rule (such as modus ponens)?

Different precisifications of Paradox can be distinguished depending on how the force of the modal "it is possible ..." is understood. One precisification is epistemic. The Epistemic Paradox arises when one asks what justifies one in reaching the conclusion of an argument by a logical rule:

Epistemic Paradox How is justification of basic forms of arguments (such as an argument by modus ponens) possible?

In this essay, I will have little to add to the standard discussions of the Epistemic Paradox (e.g., Dummett 1973; Stroud 1979; Fumerton 1995; Boghossian 2000; Philie 2007; Besson 2012, 2018). I concur with those who think that the resulting regress can and should be stopped by allowing that one might be non-inferentially justified in believing that certain patterns of entailment hold (cf. Audi 1986; Williamson 1997; Dogramaci 2010). A solution to the Epistemic Paradox such as this might say nothing about the Structural Paradox, for it might say nothing about how it is possible to give an argument by modus ponens in a conceptual (or even metaphysical) sense:

Structural Paradox How is it conceptually (or metaphysically) possible to give an argument by a logical rule?

The Structural Paradox, as I will understand it, differs from a version of the paradox that arises from understanding the modality in terms of cognitive possibility:

Cognitive Paradox How is it cognitively possible to give (or make) an argument by a logical rule?

Although the Structural Paradox and the Cognitive Paradox have the same subject matter - they both concern the act of giving (or making) an argument - the sense of 'possible' that is relevant for the Structural Paradox is not cognitive: instead, it is akin to the sense that is relevant, e.g., when philosophers ask whether coordination and communication among agents would be possible in absence of common knowledge (e.g., Lewis 1969; Stalnaker 2002). Just like standard discussions of this question abstract from psychological and cognitive assumptions of rational agents, so the Structural Paradox abstracts from the psychological and cognitive assumptions

\footnotetext{
1 A point about the terminology used throughout this essay. I will use 'argument by modus ponens' (or, more generally, 'argument by a logical rule') to indicate an argument that exemplifies the rule of modus ponens (see Sect. 2.2 for a more detailed explanation). So the speech act of giving (or making) an argument by a logical rule (e.g., by modus ponens) is the speech act of giving (or making) an argument that exemplifies that rule (e.g., the rule of modus ponens). I will often abbreviate 'giving (or making) an argument' with 'arguing' and 'giving (or making) an argument by a rule (e.g., by modus ponens)' with 'arguing by a rule (e.g., by modus ponens)'. I take it that in its core use, 'argument' refers to a linguistic entity that is the object of the speech act of giving (or making) an argument (cf. Parsons 1996; Walton 1990; Hamblin 1970, Chapter 7)). However, occasionally, I will use 'argument' to refer to the speech act of giving (or making) an argument rather than about its object.
} 
about rational argument-givers: it asks about the possibility of arguments for subjects that are, like us, capable of arguments but do not necessarily share our cognitive make-up.

One rationale for focusing on the Structural Paradox, over the Cognitive Paradox, is that Carroll (1895)'s original regress arises without making substantive psychological assumptions about argument-givers. Hence, the interpretation of the modality in Paradox that is most faithful to Carroll's original version of the regress is unlikely to be cognitive possibility. Further, the Structural Paradox is more general than the Cognitive Paradox. In virtue of this generality, as we will see, a response to the Structural Paradox might cast some light on the Cognitive Paradox too.

Now, one prominent response to the Structural Paradox contends that giving (or making) an argument by modus ponens is possible by following the rule of modus ponens. Although the rule-following account is by far the most standard diagnosis, recently it has fallen on hard times. People have raised concerns about how exactly following a rule is to be understood for this account to provide a positive diagnosis of the paradox (cf. Boghossian 2014; Valaris 2017).

And yet undeniably the rule-following account retains many attractions. This essay aims at developing and motivating a response to the Structural Paradox that overcomes the main challenges facing the rule-following account, while at the same time vindicating its key insights. According to the proposal developed here, following a rule in the course of an argument is a matter of presupposing that the rule is valid. The lesson of Carroll (1895)'s regress is that arguments are constitutively presuppositional.

The methodological starting point of my discussion is that the Structural Paradox arises from the consideration that, despite the possibility of the regress, we do seem to be able to produce arguments by modus ponens. Thus, in order to find out how giving (or making) an argument by modus ponens is possible, it is natural to look at how we do in fact give (or make) arguments by modus ponens - the idea being that studying how we in fact give (or make) an argument by modus ponens might cast light on how it is possible to do so. Because Carroll (1895)'s Structural Paradox arises in the context of an argument given by Achilles-and because giving (or making) an argument is a speech act - the focus in this paper is the regress that arises for speech acts such as giving (or making) an argument and inferring. Although there are differences between the speech act of giving (or making) an argument and the speech act of making an inference, here I will focus on what these speech acts have in common. I will not be assuming that these speech acts cannot also be made privately in one's mind, as when one thinks in words. However, this essay will not explicitly discuss a version of Carroll (1895)'s paradox that arises in the context of the reasoning (cf. Boghossian 2014; Wright 2014; Broome 2013, 2014) on further substantive assumptions about reasoning is-in particular, if one endorses the so-called taking condition on reasoning (Longino 1978; Boghossian 2014). Although the response that I will defend to the Structural Paradox can be extended to this version of the regress too, I have to leave a detailed defense of this claim to another occasion. ${ }^{2}$

2 Pavese (2020) extends the response developed in this essay to the case of reasoning. 


\subsection{The plan}

In Sect. 2, I start by discussing a widely endorsed—but not fully developed—diagnosis of the paradox, which I will call the 'common diagnosis'. According to it, the root of the regress is the distinctive structure of arguments. The common diagnosis is often assimilated to the rule-following account. I discuss some outstanding problems facing the rule-following account and I motivate developing a response to the Structural Paradox by elaborating a theory of the speech act of giving an argument.

How does one study a speech act? Speech acts are conventionally associated with certain grammatical constructions. For example, asserting is conventionally associated with declarative mood, questioning with interrogative mood, and ordering with imperatival mood. Theories of assertions, questions, and orders usually proceed from a semantic theory of their conventionalized mood. ${ }^{3}$ Just like other speech acts, the speech act of giving an argument is conventionally associated with some linguistic constructions, primarily — but, as we will see, not exclusively — with discourses of the form " $P_{1}, \ldots, P_{n}$. Therefore, $C$ ". In order to develop a theory of the speech act of giving an argument, I propose we look at the semantics of arguments, starting from the semantics of argument connectives such as 'therefore'. Following and improving on Pavese (2017), Sect. 3 argues that argument connectives are presupposition triggers.

How does the proposed semantics bear on a theory of the speech act of giving (or making) an argument? Sect. 4 makes a preliminary proposal, which is then refined by looking at premise-less arguments and arguments without argument connectives. According to the resulting theory, giving an argument is possible only by taking certain entailment relations for granted. Giving an argument by a logical rule comes out as a specific case, wherein the entailment relations one takes for granted are formally codifiable.

With a theory of arguments under our belt, Sect. 5 develops a response to the Structural Paradox. I propose that the lesson of the regress is that arguments are constitutively presuppositional. I show that the resulting theory of arguments affords a satisfactory response to the Structural Paradox as well as an explanatory account of why the structural regress can arise. Section 6 is devoted to a comparison with extant versions of the rule-following account: I argue that the response overcomes the main problems facing them, while retaining the rule-following account's key insights. In particular, my proposal allows to overcome a revenge regress that faces the intentional construal of rule-following and can be shown to be more explanatory than a merely dispositional construal of rule-following. Section 7 rebuts some objections. Section 8 concludes by returning to the Cognitive Paradox to locate the proposed solution within a bigger picture of speech acts and communication.

\footnotetext{
3 Thus, for example, Stalnaker (1987)'s theory of assertion as consisting in adding a proposition to the common ground proceeds from a standard semantics that assigns propositions to sentences with declarative mood; Roberts (2018)'s theory of questions as imposing a partition on the common ground proceeds from a standard semantics that associates sentences with interrogative mood with sets of exclusive propositions (Groenendijk and Stokhof (1984)). Finally, the theory of orders as imposing preference ranking on the common grounds (Portner 2016; Starr 2020) proceeds from a semantics that assigns sentences with imperative mood with properties rather than with propositions (Portner 2004, 2007).
} 


\section{The set-up}

\subsection{A common diagnosis}

One of the very first documented reactions to Lewis Carroll's regress comes from Russell (1903, Sect. 38) who affirms that in order to overcome Carroll's paradox:

... we need, in fact, the notion of therefore, which is quite different from the notion of implies...

Later, Winch $(1958,53)$ concurs with Russell's diagnosis when he tells us:

The actual process of drawing an inference ... is something which cannot be represented as a logical formula.

Perhaps even more explicitly, Dummett $(1973,303)$ states that Lewis Carroll's 'discovery'...

... was that an argument of the form (A) cannot be identified with the conditional (B):

(A) P. if P then Q. Therefore, Q.

(B) If $\mathrm{P}$ and if $\mathrm{P}$ then $\mathrm{Q}$, then $\mathrm{Q}$.

More recently, Smiley $(1995,725)$ also echoes Russell and Dummett:

Carroll's problem arose from his failure to distinguish between a deduction and the statement of a hypothetical proposition.

What these verdicts have all in common is the idea that the regress brings out the contrast between arguments and argument schemas, on one hand, and conditionals and conditional schemas, on the other. Call this the 'common diagnosis'.

\subsection{The rule-following account}

As it stands, the common diagnosis does little to address the Structural Paradox. Structural Paradox asks how it is possible to give an argument by modus ponens, in the light of the regress. Just saying that arguments are not the same as conditionals does not answer this question, unless it is explained how giving an argument is different from making a conditional assertion in such a way that is relevant to stopping the regress.

The rule-following account is a prominent way of developing the common diagnosis into a more direct response to the Structural Paradox. According to the rule-following account:

Claim 1: Rules are distinct from principles.

Claim 2: Giving (or making) an argument by a rule is possible by following that rule. 


\footnotetext{
${ }^{4}$ Because every true logic principle expresses the same coarse-grained proposition-the set including every possible world - 'the proposition expressed by a sentence $s$ ' in this context should not be understood as the set of possible worlds where $s$ is true. Rather, in this context, propositions are to be understood either as linguistically structured propositions (cf. King 2007) or as metalinguistic propositions-the set of possible worlds where $s$ expresses a truth in the relevant language, along the model of Stalnaker (1978)'s diagonal propositions.

5 In this characterization of logical rules, I am following MacFarlane (2004), who proposes we think of formal/logical validity as a property of argument schemas, and of formal/logical entailment as a relation between schematic premises and schematic conclusions.
} 


\subsection{A dilemma for the rule-following account}

Now, rule-following can be understood either in merely dispositional terms or in intentional terms. According to the (merely) dispositional construal, following a rule is a matter of being disposed to conform to that rule in the appropriate circumstances and this disposition is not itself partly or entirely grounded on an attitude of the rulefollower that has the rule as its content. According to an intentional construal, instead, following a rule is a matter of being guided by the rule, where being guided by a rule involves grasping the rule-i.e., standing in an attitude that has the rule as its content. As Boghossian (2014) has recently pointed out, it is not clear that either construal of the rule-following account can afford a satisfactory answer to QUESTION. ${ }^{6}$

The problem with the merely dispositional construal of rule-following is that it seems to simply postpone an answer to QUESTION. We wanted to know how giving an argument by modus ponens is possible without regress. Now, we are told (only) that giving an argument by modus ponens is possible by manifesting the disposition to conform to that rule. One might be forgiven for thinking that that is exactly what ought to be explained by a satisfactory solution of the structural paradox-i.e., how conforming to the rule is possible, without regress. The appeal to mere dispositions by itself does not help, for mere dispositions cannot explain themselves (Boghossian (2014, p. 14); Fodor (2008)). ${ }^{7}$

This suggests we should look for a more substantive account of what conforming to a rule amounts to. According to the intentional construal, giving an argument by modus ponens is possible by being guided by that rule and this in turns requires an attitude towards that rule. As I understand it, the intentional construal is not incompatible with thinking of rule-following in dispositional terms. What truly distinguishes the intentional construal from the merely dispositional construal of rule-following is that on the intentional construal, the relevant rule-following dispositions are explained at least in part in terms of guidance by an attitude of the rule-follower towards the relevant rule.

"The worry with the intentional construal of rule-following is that it seems to run afoul of what we might call a 'revenge regress'." If rule-following is a matter of being guided by an attitude towards a rule, then the rule ought to be sufficiently general to

\footnotetext{
6 Although Boghossian (2014) focuses on the version of the regress that arises for reasoning, on the assumption that the so-called taking condition holds for reasoning, the dilemma he raises also extends to Lewis Carroll's original version of the regress that, as we have seen, arises in the context of an argument.

7 People have responded to this argument in a variety of ways. Broome (2014, p. 21) tries to address this objection by proposing that one reasons from $\mathrm{P}$ to $\mathrm{C}$ provided that (i) one's belief $\mathrm{P}$ causes one's belief $\mathrm{C}$; (ii) one reaches $\mathrm{C}$ by following a rule and (ii) that doing so 'seems right to one.' However, this proposal runs into several possible counterexamples (Valaris 2017). Moreover, dispositionalism faces many other problems (cf. Pavese 2020). For example, we would want an account of following a rule that could be appealed to in an explanation of how one might come to justifiably endorse a conclusion by reasoning in a certain manner. But how can a disposition to follow a rule justify a transition? Dispositions to follow rules are not the sort of things that could justify you in acting in the way you are disposed to act (Wittgenstein (1953, p. 258); Kripke (1982)).
} 
guide one in a variety of circumstances. If so, the question arises of how the rule guides one in a specific case. On a prima facie plausible Application Model, rules guide by being applied - where applying a rule consists in going through an inference of the following sort:

\section{Application Model}

a the rule requires/licenses doing $\mathrm{X}$,

b the present case falls under the rule and in this case doing $\mathrm{X}$ would amount to doing $\mathrm{Y}$

C the rule requires/licenses doing $\mathrm{Y}$ in the present case.

For example, on the Application Model, following the rule of modus ponens in an argument would require that one appreciate that the rule of modus ponens licenses conclusions of the form $Q$ from premises of the form $P$ and If $P$ then $Q$, that one check whether the premises, e.g., Mary is Italian and if Mary is Italian then she is European has the form $P$ and If $P$ then $Q$, and that one conclude that the rule licenses the conclusion Mary is European. In other words, following the rule would require making an inference to what the rule requires/licenses in the present case. But this inference itself, qua inference, will also presumably require following a rule. This in turn will require applying the rule to the specific case at issue, and hence will require making another inference, which will also be rule-guided. And so on. A revenge regress threatens the intentional construal of rule-following when understood along the Application Model. ${ }^{8}$

\subsection{Taking stock and planning forward}

Let us take stock. The rule-following account gives a prima facie satisfactory response to the Structural Paradox, by telling us that giving an argument by modus ponens is possible by following a rule. But trouble arises when one asks what following a rule amounts to. The merely dispositional construal fails to provide an explanatory account of rule-following. The intentional construal promises to do better, by explaining rule-following in terms of being guided by a rule. But on the Application Model of what guidance amounts to, the intentional construal of rule-following faces a revenge regress. As a way of overcoming his dilemma, Boghossian (2014) recommends adopting a sort of primitivism on which rule-following is taken as an unexplained primitive. But as he points out, primitivism simply gives up on the project of reaching an explanatory account of rule-following.

Can the intentional construal of rule-following explain guidance by a rule without facing the revenge regress? This is where, I suggest, looking at how we in fact argue might help - the idea being that a study of how we do in fact argue might cast light on how giving an argument by a logical rule is possible without regress. As we will see, this study of arguments will motivate unpacking the common diagnosis into a diagnosis

\footnotetext{
${ }^{8}$ For a discussion of the application model (Boghossian 2003; Padro 2015; Boghossian 2014; Valaris 2017; Besson 2019).
} 
which retains the key insights of the rule-following account but can overcome the aforementioned difficulties.

\section{Argument connectives as presupposition triggers}

Consider the following argument:

Argument 1 Mary is English. Therefore, she is brave.

What is the contribution of the argument connective 'therefore' to it? Grice (1975, pp. 44-45) famously put forward an answer to this question:

If I say (smugly), "He is an Englishman; he is, therefore, brave," I have certainly committed myself, by virtue of the meaning of my words, to its being the case that his being brave is a consequence of (follows from) his being an Englishman. But while I have said that he is an Englishman and said that he is brave ... I do not want to say that my utterance of this sentence would be, strictly speaking, false should the consequence in question fail to hold. So some implicatures are conventional ...

According to Grice, an argument such as Argument $\mathbf{1}$ asserts its premise (that Mary is English) and asserts its conclusion (that Mary is brave). But because of the contribution of 'therefore', in addition to asserting its premise and its conclusion, Argument 1 also communicates Target Content-i.e., the proposition that Mary's being brave follows from her being English:

Target Content That Mary is brave follows from the proposition that Mary is English.

Generalizing, Grice thought that in virtue of the contribution to it of 'therefore', an argument of the form of Argument Schema communicates Target Content Schema:

Argument Schema $P_{1}, \ldots, P_{n}$. Therefore $C$.

Target Content Schema $C$ follows from $P_{1}, \ldots, P_{n}$.

Why did Grice think that? Grice's rationale for thinking that, e.g., Target Content is communicated by Argument 1 is that, by using Argument 1, one clearly commits oneself to Mary's being brave following from her being English. Hence, Target Content must be communicated by Argument 1. Though communicated by Argument 1, Grice thought that Target Content is not asserted by Argument 1. That is so because asserted/said content can be directly challenged. For example, one could challenge the premise asserted by Argument 1 by saying "That is false: Mary is not English!". Similarly for its conclusion. The fact that its premise and its conclusion can be directly challenged is evidence that Argument 1 asserts both that Mary is brave and that Mary is English. By contrast, although Target Content is communicated by Argument 1, one could not challenge Target Content directly by using "That is false" in reply to Argument 1. In fact, the contrast between (1-a) and (1-b) is striking:

(1) a. Mary is English. Therefore, she is brave. *That is false/That is not true.

b. From the fact that Mary is English, it follows from that that she is brave. That is false/that is not true. 
Note that both (1-a) and (1-b) communicate the proposition that Mary's being brave follows from her being English. In other words, they both communicate Target Content. But whereas this proposition can be directly challenged in (1-b), the same proposition cannot be directly challenged in (1-a). This is evidence that, although Target Content is conveyed by Argument 1, it is not asserted by it. On the basis of these considerations, Grice concluded that Argument 1 asserts that Mary is English, asserts that she is brave, and also communicates Target Content but without asserting it.

What is, exactly, the status of Target Content, then? The fact that Target Content cannot be directly challenged by itself is compatible with Target Content being entailed by Argument 1. For example, "Mary is English" entails that "Mary is European," but one could not challenge the proposition that Mary is European simply by using "That is false" in response to "Mary is English." Along similar lines, one might think that, when one uses Argument 1, one entails that Mary's being brave follows from her being English without explicitly asserting it.

However, as Pavese (2017) has argued, several considerations tell against the entailment analysis. ${ }^{9}$ Like Grice, Pavese observes that by using Argument 1, one commits oneself to Mary's being brave following from her being English. Hence, Target Content must be conveyed by Argument 1. However, she argues that Target Content is not entailed nor asserted by Argument 1. Rather, it is conveyed via a presupposition. According to Pavese (2017), primary evidence for this claim is that argument connectives such as 'therefore' satisfy the usual linguistic tests for presupposition triggers. Spelling out Pavese (2017)'s argument for this conclusion requires some steps.

A prominent test for spotting presupposition triggers is the projection test: the crucial difference between entailment and presuppositions is that the latter project out of embeddings (Karttunen 1973, 1974; Beaver 2001). For example, consider (2-a):

(2) a. It is the knave that stole the tarts.

b. The knave stole something.

c. Somebody stole the tarts. Target Content*

(2-a) entails (2-b): it is a sign that (2-a) entails (2-b) that if one embeds (2-a) under negation, the resulting sentence does not convey (2-b) any longer. For example, the negation (3-a) does not convey (2-b) any longer. By contrast, consider (2-c). It is a sign that the proposition expressed by (2-c) is presupposed by (2-a) - rather than entailed or explicitly stated by (2-a) — that if one embeds (2-a) under negation (3-a), under a question (3-b), in a conditional (3-c), under a possibility modal (3-d), or an evidential modal (3-e), the resulting sentences still convey the proposition expressed by (2-c). Because the proposition expressed by (2-c) — Target Content* —is still conveyed by (3-a)-(3-e), Target Content* passes the projection test and that is evidence that it is presupposed by (2-a) - rather than entailed or asserted by (2-a):

a. It is not the knave that stole the tarts. (Negation)

b. Is the knave that stole the tarts? (Question)

\footnotetext{
9 Other argument connectives, such as 'hence' and 'so', are also presupposition triggers. Because differences between different argument connectives will not matter, for simplicity here I will just focus on 'therefore'.
} 
c. If it is the knave that stole the tarts, he will be punished. (Antecedent of Conditionals)

d. Maybe/It is possible that it's the knave that stole the tarts. (Possibility Modals)

e. Presumably/probably, it's the knave that stole the tarts. (Evidential modal, probability adverb)

Now, what we want is to use the projection test to see whether, e.g., Target Content is presupposed by Argument 1 (rather than entailed or asserted). In order to do so-by analogy with how we showed that Target Content* is presupposed by (2-a) we would have to embed Argument 1 under negation, questions, conditionals, and modals, and then see if Target Content is still communicated by the resulting constructions. But a difficulty arises: Argument 1 cannot be embedded as it is, because it is not a sentence but, rather, a discourse.

To remedy this, we ought to turn Argument 1 into a sentence. We can easily do so, by turning the period in it into a conjunction and a comma. This gives us:

Argument 2 Mary is English and, therefore, she is brave.

Like Argument 1, Argument 2 also conveys Target Content, for the same reasons Argument 1 does: by uttering Argument 2, one also commits oneself to Mary's braveness following from her being English. But Argument 2 is a sentence, and so it can embed within wider linguistic contexts. So Pavese (2017)'s idea was that, in order to find out whether Target Content is presupposed by Argument 1, we see if it is presupposed by Argument 2-i.e., we look at whether Target Content projects when Argument $\mathbf{2}$ is embedded within wider linguistic contexts.

So, now, what happens when Argument 2 is embedded under negation and other linguistic environments? Interestingly, just like a presupposition, Target Content projects out of embeddings, of antecedents of conditionals (4-a), of questions (4-b), ${ }^{10}$ as well as out of negation (4-c), possibility modals (4-d), and evidential modals (4-e), as can be seen from the fact that all of (4-a)-(4-e) still convey that Mary's being brave follows from her being English:

(4) a. If Mary is English and, therefore, brave, she will act as such. (Conditional)

b. Is Maria English and, therefore, brave? (Question)

c. It is not the case that Mary is English and, therefore, brave. (Negation)

d. It might be that Maria is English and, therefore, brave.s (Possibility Modals)

e. Presumably, Mary is English and, therefore, brave. (Evidential modal, probability adverb)

Consider, for example, (4-b): it does not ask whether Mary's braveness follows from her being English. Rather, it asks whether Mary is English. Consider how unnatural it would be to reply to (4-b) by 'No', simply on the ground that Mary's braveness does not follow from her being English, even though the speaker knows that Mary is English. Hence, Target Content can project from embeddings just like presuppositions do.

10 See also Neta (2013, pp. 394-395). 
On these bases, Pavese (2017) argued that Target Content passes the first main test for being presupposed by Argument 1. The second main linguistic test for presuppositions is the not-at-issuedness test, which we have already discussed in part. Presuppositions cannot be directly challenged-i.e., for example, one cannot directly challenge the presupposition in (2-a) with (5):

(5) *That is not true/That is false!

If one were to use (5) in response to (2-a), one would be challenging the claim that the knave stole the tarts-not the presupposition that somebody stole the tarts. But as we have seen at the outset, when conveyed by Argument 1 (or Argument 2), Target Content above satisfies also the not-at-issuedness test, for when conveyed by those constructions, it cannot be directly challenged, as evidenced by infelicity in the initial (1-a).

This is not to say, of course, that arguments cannot ever be challenged. For example, (6-a)-(6-c) do challenge Argument 1's Target Content:

(6) a. Wait a moment! Mary's braveness does not follow from her being English!

b. Wait a minute! That argument is not valid.

c. Hey, wait a minute! Not all English people are brave!

However, this way of challenging Target Content is indirect, for notice that it requires taking distance from the at issue-content of the argument. In fact, Von Fintel (2004) and Tonhauser et al. (2013) use the 'wait a minute' test precisely for spotting presupposition triggers. This test uncovers the presence of presupposition triggers by testing for whether presuppositions can be indirectly challenged, as when we reply to (2-a) by (7) with locutions such as 'wait a minute':

\section{(7) Wait a minute! Nobody stole the tarts!}

In conclusion, the two main tests for spotting presuppositions-the projection test and the non-at-issuedness test-suggests that Target Content is presupposed by Argument 1. Because the same results are obtained by changing examples, generalizing, these tests suggest that propositions of the form of Target Content Schema are presupposed by arguments of the form of Argument Schema. Pavese (2017) concluded that 'therefore' satisfies the two main tests for presupposition triggers.

The final consideration that Pavese (2017) put forward on behalf of the presuppositional analysis of 'therefore' is that the machinery of local contexts - standardly invoked in the study of presuppositions (e.g., Heim 1983; Karttunen 1974; Rothschild 2011; Schlenker 2009, 2010) - enters center stage in an explanation of the contextsensitivity of constructions embedding 'therefore'. For example, consider (8):

(8) Mario is progressive. Therefore, he is from the North of Italy.

Although one's geographical origins are surely not entailed by one's political preferences and although in many contexts arguing as in (8) would not be felicitous (for in Italy being progressive is hardly an indication of one's origins), the argument in (8) could be given felicitously in a context where a sociological experiment is conducted 
with a group of subjects that includes Mario and where all the progressive subjects of the experiment turn out to come from the North. The presuppositional analysis can predict this pattern of context-sensitivity for it is commonly accepted that presuppositions are satisfied relative to their so-called local contexts: the local context for ' $\mathrm{He}$ is, therefore, from the North' in (8) - the global set of assumptions in the current context augmented with the sentence 'Mario is a progressive'-supports that Mark is from the North.

These are the main arguments given by Pavese (2017) for the presuppositional analysis of 'therefore'. Many other considerations — not discussed by Pavese (2017) — point in favor of the same analysis. First of all, the presuppositional analysis of 'therefore' provides a natural explanation for why (8) sounds Moorean-paradoxical Hlobil (2014, p. 421):

(9) ??Mary is English. Therefore, she is brave, but I do not believe/know that her being brave follows from her being English.

For it is a general fact about presuppositions that they cannot be canceled if unembedded and that commitment to the presupposed content cannot be retracted, on pain of Moorean paradoxicality, as evidenced by the weirdness of the following continuations:

(10) It is the doctor who stole the tarts. ??But nobody did. ?? But I do not believe/know that anybody stole the tarts.

Moreover, Target Content can be canceled when embedded, as in (11), which is exactly what one would expect if it were presupposed:

(11) Mark is under the impression that Mary is English and therefore brave. But of course her courage does not follow from her being English.

In addition, 'therefore' satisfies additional tests for strong presupposition triggers suggested by Pearson (2010) and Abrusán (2016). Strong presuppositions triggers such as 'stop' cannot felicitously follow a report where the speaker retracts commitment to their presuppositions Pearson (2010), as in (4-b) and (12-b):

a. ??Well, I do not know if Jill ever smoked. But she stopped now.

b. ??Well, I do not know if Jill ever smoked. But Mary knows that Jill smoked.

The presuppositions of 'strong' triggers cannot even be suspended, as observed by Abrusán (2016, p. 167):

(13) a. I have no idea whether John read the proposal. But if Bill read it too, let's ask them to confer and simply give us a yes/no response. (Abusch (2010))

b. ?? I have no idea whether my husband is cheating on me. But if I discover that he is, I am going to kill him. 
In (4-b)-(12-b), a strong presupposition trigger is not licensed in the antecedent of a conditional, after a statement that expresses ignorance about whether the presupposition is true.

'Therefore' satisfies both tests: it does not felicitously follow retraction, as evidenced by the infelicity of (14-a), nor can its presupposition be suspended, as evidenced by the infelicity of (14-b):

(14) a. ??Well, I do not know if her braveness follows from her being English. But Mary is English. And therefore, she is brave.

b. ??I have no idea whether all English people are brave. But if Mary is English and therefore brave, she will act as such.

On this diagnostics, 'therefore' qualifies as a strong presupposition trigger.

Does the fact that 'therefore' satisfies all of these tests for presupposition triggersi.e., non-at-issuedness, projectability, context-sensitivity, and cancelability-tell against the main alternative explanations to the presuppositional analysis? The main alternative explanation, that as we have seen was mentioned en passant by Grice in the passage quoted, is that Target Content is conventionally implied by 'therefore'. ${ }^{11}$ Now, many philosophers and linguists have pointed out that the boundaries between conventional implicatures and presupposition triggers are notoriously hard to draw (e.g., Karttunen and Peters 1979; Potts et al. 2005; Potts 2007, 2015). However, the recent literature has developed more refined tests for telling apart presuppositions and conventional implicatures.

Potts (2015, p. 31) proposes we distinguish presuppositions and conventional implicatures on the basis of their pattern of projectability - the idea being that conventional implicatures project even more massively than presuppositions. Consider appositives - a paradigmatic example of conventional implicatures (cf. Potts 2007, p. 668). They mandatorily project out of standard plugs such as attitude reports:

George believes that Mary, who is fun, is not fun.

This criterion proposed Potts (2015, p. 31) speaks in favor of the presuppositional analysis for 'therefore', for the content associated with 'therefore' can be plugged by belief reports:

(16) George believes that Mary is English and, therefore, brave. (Belief operator)

(16) can certainly be used to ascribe to George not just the beliefs that Mary is English and that she is brave, but also the (implicit) belief in the entailment from Mary's being English to her being brave. On this reading, Target Content does not project from (16).

Presuppositions project less massively than paradigmatic examples of conventional implicatures such as appositives also in a second respect. As Mandelkern (2016) has observed, the content of appositives projects even when it is locally entailed. For example, 'who is fun' still projects in sentences such as (17-a) and (17-b):

11 Others have followed Grice (1975) in this. See, e.g., Potts (2007, p. 2) and Davis (2014, Sect. 2). Bach (1999), Bach (2006, Sect. 10) argue against Grice (1975)'s view. 
(17) a. If Mary is fun, then she'll, who is fun, come to the party.

b. If Mary is fun and Mary, who is fun, is in town, then she'll come to the party.

By contrast, the presupposition associated with 'stop' (that Mary used to smoke) projects from (18-a) but does not project from either (18-b) or (18-c), where the proposition that Mary used to smoke is already locally entailed:

a. If Mary stopped smoking then she can come to the party.

b. If Mary used to smoke then she stopped smoking.

c. If Mary used to smoke and she stopped smoking then she can come to the party.

On the basis of this and other similar observations, Mandelkern (2016, p. 392) suggests the following necessary condition for presuppositions:

Lack of preservation : If an assertion of a sentence $s$ licenses an inference to a proposition $p$ in a context $c$, then $s$ presupposes $p$ in $c$ only if $s$ does not warrant an inference to $p$ when $p$ is locally entailed.

Lack of preservation also is satisfied by discourses featuring 'therefore'. For example, Target Content projects in (19-a) — where it is not locally entailed — but not from (19-b) or (19-c) — where it is locally entailed:

a. If Mary is English and, therefore, brave then she will act bravely.

b. If being English entails being brave, then Mary is English and, therefore, brave.

c. If being English entails being brave and Mary is English and, therefore, brave, then she will act bravely.

Hence, 'therefore' satisfies another necessary condition for presupposition triggers that standard conventional implicatures such as appositives do not satisfy.

Before closing this discussion, let me clarify that the claim that 'therefore' is a presupposition trigger is compatible with the relevant Target Content sometimes not projecting out of embeddings. For example, as some speakers report, (4-c) can also have a non-projective reading. On this non-projective reading, we are not simply denying that Mary is English. We might be denying that her braveness follows from her being English. The presence of this projective reading is, however, compatible with "therefore"s being a presupposition trigger. For it is generally the case that negated sentences embedding presupposition triggers license non-projective readings. For example, consider (20):

(20) The tarts were not stolen by the knave: there is no knave.

In (20), the presupposition that the knave exists obviously does not project. Several possible explanations for non-projective readings under negation have been proposed. ${ }^{12}$

12 According to one such explanation (Horn (1985)), negation is ambiguous between a presuppositionpreserving negation and a presupposition-denying negation (cf. Beaver and Geurts 2014.) According to another, we might be dealing with an example of local accommodation (Heim 1983). For an overview of these issues, (see Pavese 2021). 
Whatever explanation works best for the non-projective reading of (20) can plausibly be extended to explain the non-projective reading of (4-c). So, 'therefore"s being a presupposition trigger is compatible with there being non-projective readings of the discourses where 'therefore' features, in so far as the general pattern of projection is otherwise alike that of other presuppositions. What seems clear is that the pattern of projection of the content contributed by 'therefore' aligns much more clearly with that of presupposition triggers than with that of conventional implicatures, in that it can be plugged by belief reports and does not project when locally entailed. I conclude that the evidence is overwhelming that, when it comes to argument connectives such as 'therefore', we are dealing with genuine presupposition triggers.

\section{A theory of arguments}

\subsection{Presupposing a rule versus presupposing an instance of the rule}

If 'therefore' is a presupposition trigger, what follows about the structure of arguments?

The discussion in the last section motivates taking arguments of the form of Argument Schema to convey that $C$ follows from $P_{1}, \ldots, P_{n}$ through a semantic presupposition. Semantic presuppositions are properties of sentences and discourses types and, as such, are not to be confused with pragmatic presuppositions - which are instead attitudes that one holds towards a proposition in virtue of taking its truth for granted. Yet, semantic presuppositions are related to pragmatic presuppositions by certain bridge principles. In particular, following Stalnaker (1975), we can assume that, if a discourse $d$ semantically presupposes $p$, then one would, by using $d$, pragmatically presuppose $p$. If so, if $d$ semantically presupposes $p$, then one would, when using $d$, take for granted that $p \cdot{ }^{13}$ If so, then this semantic analysis tells us something interesting about the speech act of giving an argument-i.e., that when arguing from ' $P_{1}, \ldots, P_{n}$ ' to ' $C$ ', one takes for granted that $C$ follows from $P_{1}, \ldots, P_{n}$.

As it stands, however, the current analysis is incomplete. When one argues from 'Mary is English' to 'Mary is brave', one is not just presupposing that her being brave follows from her being English. Plausibly — and whether knowingly or not—one presupposes that Mary's being brave follows from her being English by presupposing something more general - that quite generally English people are brave. After all, as we have seen, both (6-a)-(6-c) above are legitimate ways of challenging Argument 1. Moreover, this more general presupposition can be seen to project out of embeddings (4-a)-(4-e), just like the more specific one. Finally, one's presupposing that English quite generally are brave explains one's disposition to presuppose that Mary's braveness follows from her being English in the course of arguing from 'Mary is English' to 'Mary is brave'.

Now, consider an argument by modus ponens. As the presupposition tests suggest, this sort of argument presupposes that the conclusion follows from those premisesi.e., that an instance of modus ponens holds. By analogy with the previous case, however, it seems that at least in many cases, by giving an argument by modus ponens,

13 Cf. (Stalnaker 1977, 2002). 
whether knowingly or not, one presupposes that an instance of the rule holds by presupposing something more general-i.e., that the rule is generally valid. After all, this more general presupposition too can be indirectly challenged (e.g, "Wait a moment! Not every instance of MP is valid!") and just like the more specific one, it can be seen to project out of embeddings. Finally, and very importantly, one's presupposing that the rule is valid would explain one's disposition to presuppose that an instance of the rule holds in an argument by that rule.

How plausible is it that in arguments by modus ponens, one presupposes that that rule is valid? In some cases, it is pretty clear that one does: consider a logic teacher who develops a proof on the board and who reaches the conclusion by saying " $\mathrm{C}$, by modus ponens." It is overwhelmingly plausible that in this case, the teacher is taking for granted, and asking others to take for granted, that the general rule of modus ponens is valid.

Yet, one might think that not every argument by modus ponens can presuppose the general validity of the rule. Consider for example, Professor Vann McGee, who famously does not believe that modus ponens is generally valid (McGee 1985) and hence presumably would not be disposed to presuppose the validity of this rule. Yet, Vann McGee can still argue by modus ponens.

In response, could not Professor McGee be presupposing only that a suitably restricted rule is valid? That is compatible with him being skeptical that the rule does not have any counterexample. Yet, it might seem implausible that in every argument by modus ponens, what is presupposed is something about rules, their validity, or their restrictions thereof. After all, we start arguing by modus ponens well before we know anything about logical rules and validity. Think of the average pre-college individual arguing by modus ponens: are they really presupposing its validity? Whatever stance we take on this question, it would be nice to have a way of distinguishing arguments one makes by invoking a rule (as the logician case) from arguments where a rule is not explicitly invoked (as in more ordinary cases). Just saying that, in both cases, the validity of the rule is presupposed, in the same exact way, will not account for this intuitive distinction.

These considerations suggests the following unifying strategy. As our presupposition tests suggest, I will take arguments to presuppose that their conclusion follows from their premises. And I will take arguments to presuppose that in virtue of presupposing something more general-i.e., that a general rule, or a suitable restriction thereof, is valid. But while in some cases - as when one invokes the rule in the course of an argument-presupposing the validity of the rule is a matter of being in a nontacit presuppositional attitude towards that rule, in other cases, one presupposes it in a weaker, tacit, sense. As Lewis (1969, pp. 64-68) puts it, this is the sense in which competent speakers of their language presuppose the semantic conventions for the language they speak, while being unable to articulate them: 'non-knowingly': 'nonverbally', 'tacitly', or even in sensu diviso. According to this proposal, that a rule - or a restriction thereof-is valid in one's language is just one among the semantic conventions that one presupposes (tacitly or not) when speaking that language. Positing 
this presupposition is explanatory as it explains our coming to see and presuppose that an instance of the rule holds in the course of an argument by that rule. ${ }^{14}$

The next subsection shows how to model the presuppositional aspect of 'therefore', assuming a dynamic approach to the semantics of arguments. Because the general argument developed in this essay does not depend on this particular semantic proposal-which has the illustrative purpose of making the general proposal formally cogent - the reader can skip it and jump to Sect. 4.3 without losing any step in the philosophical argument.

\subsection{A dynamic analysis}

On a dynamic treatment of presuppositions, it is natural to think of presuppositions as special kinds of tests. In dynamic semantics, a test is an expression whose function is to check whether the context satisfies certain constraints. The most paradigmatic example of a test is Veltman (1996, p. 9)'s 'might':

\section{Dynamic Might $c[$ might $-\phi]=$}

- $c$, if $c+\phi \neq \emptyset$;

- $\emptyset$, if $c+\phi=\emptyset$.

Dynamic Might is a test that checks whether the context $c$ is compatible with the prejacent $\phi$. Let $\langle\phi\rangle$ be the set of possible worlds where $\phi$ is true and let a context $c$ augmented with $\phi(=c+\phi)$ be the intersection of $c$ with the set of $\phi$-worlds- the worlds where $\phi$ is true $(=c \cap\langle\phi\rangle)$. Dynamic Might returns the context $c$ if $\mathrm{c}+\phi$ is not empty and it returns the empty set if $c+\phi$ is empty-if $\phi$ is not compatible with $c$.

From Dynamic Might plus Duality, we get another test-Dynamic Must — which also runs a test on the context but this time it checks whether the context supports $\phi$ (von Fintel and Gillies (2007, p. 54); Willer (2013)):

Duality must $-\phi=\neg$ might $\neg-\phi$.

\section{Dynamic Must $c[$ must $-\phi]=$}

- $c$ if $c \vDash \phi$;

- $\emptyset$ if $c \not \models \phi$.

Dynamic Must above returns $c$ if $c$ supports $\phi-' c \vDash \phi$ - and the empty set if $c$ does not support $\phi$. Support between a context $c$ and a sentence $\sigma$ is defined inductively as follows:

\footnotetext{
14 According to Lewis $(1969,64-68)$, one presupposes $p$ in sensu diviso just in case one is disposed to presuppose each of its instances. However, I am inclined to think of tacit presuppositions along the lines of Stalnaker (1975)'s notion of presupposition, rather than in terms of presuppositions in sensu diviso. For Stalnaker (1975) understands presuppositions in a sufficiently liberal way to encompass tacit presuppositions. As he puts it, presupposing $p$ just in case one takes the truth of a proposition $p$ for granted, where taking the truth of $p$ for granted is an attitude one can bear to $p$ whether or not one has consciously thought about whether $p$.
} 


\section{Support}

1. If $\sigma$ has the form $p, c \vDash \sigma$ just in case, $p$ is true at every world in $c$-i.e., for all $w \in c: w \in<p>$;

2. If $\sigma$ has the form $\neg \phi, c \vDash \sigma$ just in case $c \not \models \phi$;

3. If $\sigma$ has the form $\phi \& \psi, c \vDash \sigma$ just in case $c \vDash \phi$ and $c \vDash \psi$.

'Therefore' is similar to 'must': 'must' imposes that the context supports a conclusion and 'therefore' imposes that the context augmented with the premises entails the conclusion. But 'must' and 'therefore' also differ in important ways. For one thing, 'must' is not plausibly a presupposition trigger. For example, (21) is not infelicitous if it is not known in the context that Mary is in Holland:

If Mary must be in Holland, she cannot be in Paris.

Pavese (2017)'s suggestion is that 'therefore' differs from other tests, in that the checking is done by the presupposition triggered by 'therefore', rather than by its core content. 'Therefore'-discourses are infelicitous if the checking is not positive, like in the case of 'must'-sentences. But in the case of 'therefore', the infelicity is due to presupposition failure. If so, in order to capture "therefore"s distinctive projective behavior, it is best to model the semantic entry for 'therefore' along the lines of Beaver (2001, pp. 156-162)'s presuppositional operator ' $\delta$ ':

$$
\text { Dynamic } \delta c[\delta-\phi] \begin{cases}c & \text { if } c \vDash \phi \\ \text { undefined } & \text { if } c \not \models \phi\end{cases}
$$

Dynamic $\delta$ is also a test—and it also tests for whether the context supports $\phi$ but is a special kind of test, in that it returns 'undefined' rather than the empty set when the context does not support $\phi$. The difference between these two 'fail' valuesundefinedness versus the empty set-is important. A semantic entry that returns the empty set receives a non-fail value - that of a tautology — under negation. But in order to account for the projection of the presupposition from a sentence containing ' $\delta$ ' to its negation, the negation of that sentence must also receive a fail value if the sentence does. Choosing 'undefined', rather than the empty set, gives the desired result-i.e., that the negation of the sentence containing ' $\delta$ ' will also be undefined.

So far so good. Now, the entry for 'therefore' cannot be exactly the same as ' $\delta$ ', because ' $\delta$ ' does not take premises. By contrast, 'therefore' can-and in fact must-have an antecedent. Note that the following antecedent-less discourses are not felicitous in English:

a. ??Therefore, streets are wet (looking at the rain pouring outside).

b. ??Therefore, either it is raining or it is not raining.

So the entry for 'therefore' ought to differ from that of ' $\delta$ ' accordingly.

With these preliminaries, consider the following dynamic entry, where $\Phi$ be a nonempty set of premises $\phi_{1}, \ldots, \phi_{n}$ and let $c+\Phi$ be the intersection of the context $c$ with every element in $\Phi\left(c+\Phi=c \cap<\phi_{1}>\cap \ldots \cap<\phi_{n}>\right.$, for every $\phi_{1}, \ldots \phi_{n}$ in $\Phi)$. In order to model the general presupposition about the validity of logical rules, the context $c$ should be thought to include also the semantic conventions that the speakers 
in that context presuppose to be true of the language they speak and that are commonly known among the participants to the conversation. Given this, consider the following dynamic entry:

$$
\text { Dynamic Therefore } c[\Phi, \text { therefore }-\psi]= \begin{cases}c[\Phi] & \text { if } c+\Phi \vDash \psi \\ \text { undefined } & \text { if } c+\Phi \not \models \psi\end{cases}
$$

According to Dynamic Therefore, the result of giving an argument is to update the context with its premises, having checked that so augmented the context supports the conclusion. Because it returns undefined, rather than the empty set, when the checking is negative, Dynamic Therefore can account for the projection of presuppositions from, e.g., a sentence such as 'Mary is English and, therefore, brave' to its negation.

Dynamic Therefore can model simple arguments of the form ' $P_{1}, \ldots, P_{n}$, therefore $C$ '. A problem with Dynamic Therefore is that it fails to capture uses of 'therefore' that have not premises but other arguments as antecedents, as when one argues by conditional proof, by reductio, or by cases. For example, consider:

\section{Argument A}

$P$, Therefore, $C$. Therefore, if $P$ then $C$.

If we apply Dynamic Therefore to this example, updating $c$ with ' $P$, Therefore, $C$ ' will return the context $c$ updated with the premise $P$. And the second 'therefore' will test for whether that context supports 'if $\mathrm{P}$ then $\mathrm{C}$ '. This is not the right interpretation of an argument by conditional proof, whose conclusion ought to discharge the premise $P$. In order to get the right interpretation of Argument A, we need to make sure that the second 'therefore' does not occur under the scope of the premise $P$. In order to achieve this result, more structure ought to be added to the argumentative discourse. Indexes can be used to this effect:

\section{Argument A}

$P_{1}$, Therefore $1, C$. Therefore 0 , if $P$ then $C$.

The fact that the index of the last 'therefore' is not the same as that of the antecedent argument's premise $P_{1}$ indicates that the conclusion of Argument A does not occur within the scope of that premise. What 'therefore ${ }_{0}$ ' tests is the context antecedent to the update with the argument ' $P_{1}$, Therefore $1, C$ '-i.e., it tests $c_{0}$, not $c_{1}$. So, capturing arguments such as Argument $\mathbf{A}$ requires imposing a syntax on argumentative discourses that can track the anaphoric relations between 'therefore' and its antecedents; it also requires contexts to be ordered as the results of subsequent updates.

Simplifying a bit, let contexts be totally ordered $\left(<c_{i}, \ldots, c_{n}>\right)$ by the number of updates that they result from. Let the initial context be $c_{0}$ and for any other $c_{n}$ such that $n>0$, let $c_{n-1}$ be defined. We are now in position to reach a more general semantic entry for 'therefore', that also covers arguments that have other arguments as antecedents. 
In this entry, 'therefore' is a unary connective (taking only one argument-i.e., its conclusion) and its index signals which context it should be understood as testing:

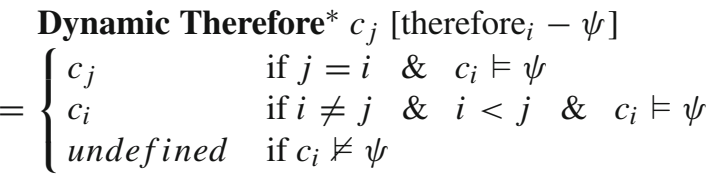

Unpacking: when the argument has a simple 'Premises + Conclusion' structure, 'therefore' is indexed to its premises and so it tests a context just updated with them. In this case, $c_{i}=c_{j}$, so the first clause kicks in. If the result of 'therefore ${ }_{i}$ ' testing the context $c_{j}$ is positive, it returns $c_{j}$. When the antecedent is a complex argument (such as an argument by conditional proof like Argument A), instead, "therefore"s index will refer back to the context prior to updating it with the premise of the subargument ' $P_{1}$. Therefore ${ }_{1}, C$ ' and in this case the second clause of Dynamic Therefore* kicks in. In conclusion, Dynamic Therefore* improves on Dynamic Therefore in that it can account for uses of 'therefore' in simple as well as in complex arguments. ${ }^{15}$

\subsection{Extending the analysis}

According to the current proposal, giving an argument requires presupposing that certain entailment relations between its antecedents and its conclusions hold. As it stands, this analysis is restricted in scope: because it is modeled along a semantics for argument connectives, it does not encompass arguments that are made without argument connectives; moreover, because it focuses on arguments with argument connectives such as 'therefore', which require an antecedent, it does not seem to cover zero-premises arguments, which have no antecedent. This section extends the current analysis to these sorts of arguments.

Arguments without argument connectives A logic teacher gives his students passages where no argument connectives are there to indicate the conclusion-where part of the exercise is to figure out the structure of the argument without linguistic flags (Exercise). ${ }^{16}$ Informal conversation may also proceed this way: with the right intonation, a connectives-free discourse with premises and conclusion can be used to make an argument. Are these practices in contradiction with the current analysis?

As is known in speech act theory, the same speech act can be made by using linguistic constructions that are different from those conventionally associated with it. Just to give one example, making a request does not also require the imperative mood, as one might request the salt by asking a question "Can you pass the salt?" The same is true for assertions and orders (cf., e.g., Roberts 2018; Murray and Starr 2020). We should expect the same to be true for arguments-i.e., that arguments can be made without using the expressions conventionally associated with them.

\footnotetext{
15 For the purpose of this paper, this sketch of the semantics will do. For a systematic discussion of the syntax and dynamics of argumentative discourse and more illustrative examples (see Kocurek and Pavese 2020).

16 I have to thank a referee for this example.
} 
If so, the observation that conventionally making a premise-conclusion argument involves the use of argument connectives by itself is not in contradiction with the fact that sometimes making an argument is possible without argument connectives. Yet, one might ask, how can arguments without argument connectives be presuppositional - as the current analysis suggests - if argument connectives are the presupposition triggers?

The answer is that when no argument connective is present, something else-e.g., discourse prosody (intonation and stress) or an implicit argument connective whose presence is signaled by prosody - triggers the relevant presupposition. This response is independently motivated. It is generally true that discourse relations do not need to be expressed by explicit discourse connectors. Consider:

Discourse John pushed Mark. Mark fell.

Discourse expresses that a relation holds between Mark's being pushed by John and Mark's falling - a relation that discourse coherentists call 'explanation' (e.g., cf. Asher 1993; Asher et al. 2003). That this explanation relation holds can also be conveyed through an explicit discourse connector, such as 'because of that'. But as Discourse shows, the relevant discourse connector does not need to be explicitly present. Discourse coherent theorists typically analyze discourses without discourse connectives on the model of those with discourse connectives - also as expressing the holding of a discourse relation but through discourse prosody and/or through 'implicit' discourse connectors (cf. Bras et al. 2001, 2009).

Now, arguments are just one type of discourses and argument connectives are just one type of discourse connectives. So we should expect something similar to be true of them. This motivates thinking that, just like arguments with argument connectives, the logical form of connective-less arguments also involves a presupposition-though in these cases the presupposition is triggered by discourse prosody or by an implicit presupposition trigger.

According to this suggestion, when in Exercise, students individuate the structure of an argument in a discourse that lacks explicit argument connectives, they succeed at individuating what marks the premises from the conclusion by locating the implicit presupposition trigger in the logical (and non-superficial) form of the argument.

Zero-premises arguments In logic and in mathematics, it is customary to allow for zero-premises arguments, such as:

$$
\overline{\psi \wedge \neg \psi}
$$

But our current theory of arguments does not encompass zero-premise arguments, for it is modeled along the study of argument connectives, such as 'therefore', which require an antecedent.

The required fix is, however, once again revealed by looking closely at our argumentative practice. In natural languages, we can express the force of zero-premise arguments by assertions such as: ${ }^{17}$

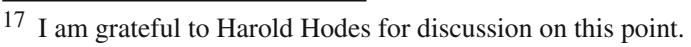


Fig. 1 Regress of presuppositions

\subsection{The response}

In (BYLOGIC), the locution 'by logic' bears a close structural similarity with the locution 'by modus ponens' discussed in the previous section. Plausibly, in this case too, the locution triggers a presupposition - this time about the validity of a set of logical rules (such as those of classical logic). By using the locution 'by logic', we are signaling that we are taking for granted —and asking our interlocutor to grant—-that a certain set of logical rules is valid (e.g., those of classical logic).

If so, then this theory of arguments can be generalized to cover zero-premise arguments too: the latter can be understood on the model of (BYLOGIC) - as premise-less assertions prefaced by (explicit or implicit) locutions such as 'by logic', 'by this logical system', or 'by this set of rules', which are made by taking for granted the validity of a set of logical rules.

\section{The structural paradox}

Our analysis affords a direct response to the Structural Paradox: according to it, giving an argument by modus ponens is possible by presupposing that certain entailment relations hold. This analysis unpacks the common diagnosis by telling us that giving an argument by modus ponens differs from asserting the corresponding conditional precisely in that when we argue by modus ponens, we presuppose-but not explicitly state- that the consequent of the conditional follows from the antecedent and we presuppose that by presupposing — but not explicitly stating — the validity of the rule.

This response to the Structural Paradox explains why Achilles cannot reach his conclusion. Arguing from premises to conclusion would require presupposing that premises entail the conclusion but this is called into question-in this sense his presupposition fails - and so no argument from premise to conclusion is possible (given the relevant reading of 'possible' in the context). Conversely, suppose it were common ground between Tortoise and Achilles that modus ponens holds. Common ground licenses conclusions: if the common ground supports a conclusion, then people sharing the same common ground will be disposed to accept it. Hence, if Tortoise had taken for granted what Achilles was taking for granted, she too would come to accept the conclusion that Achilles wants to draw (Fig. 1).

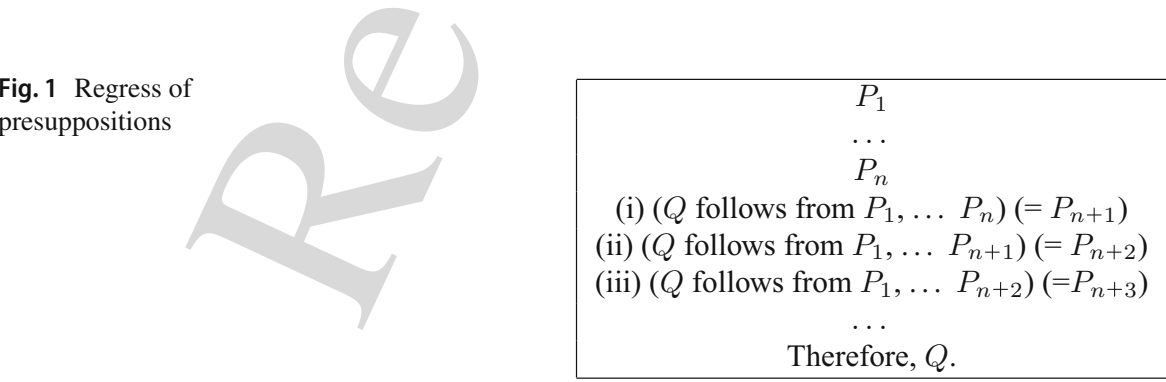




\subsection{A regress of presuppositions?}

By recognizing the presuppositional structure of arguments, we might overcome the regress of the premises. But a natural worry arises: could not a different sort of regress-i.e., a regress of presuppositions-arise?

In order to see why a regress of presuppositions is not possible, recall that presuppositions differ from premises in that they are backgrounded. What does it mean that presuppositions are backgrounded? Recall the linguistic tests that we have used to spot presuppositions. Those tests take it that for some content to be backgrounded, (1) it cannot be directly challenged (not-at-issuedness) and (2) its projective behavior shows that it resists embedding under logical operators (projective behavior).

Now, the current proposal is that an application of 'therefore' will presuppose that the premises $P_{1}, \ldots, P_{n}$ supports the conclusion $C\left(P_{n+1}\right)$. It will not additionally presuppose that $P_{1}, \ldots, P_{n}, P_{n+1}$ support the conclusion, for $P_{n+1}$ is not available as a premise for that application of 'therefore'; nor is $P_{n+1}$ available for a further application of 'therefore', unless $P_{n+1}$ gets turned into an explicit premise. For as backgrounded, that proposition eludes scoping under logical operators and resists from being picked up by demonstratives and referential devices. Thus, its being backgrounded accounts for why this proposition is 'impermeable' to a further application of 'therefore' - the successive applications of which would otherwise trigger the regress.

So, no regress can start (neither the regress of the premises nor the regress of the presuppositions), if presupposition stays backgrounded. It will start if one keeps challenging it but only because challenging it "un-backgrounds" it-i.e., it turns it into a new premise.

\subsection{Whence the infinite regress?}

The current response has the virtue of explaining two further aspects of Carroll (1895)'s original fable. One puzzling aspect of the exchange between Achilles and Tortoise is that although Tortoise is, in some sense, behaving unreasonably, somehow she is in a position to trigger the regress. What is it about Achilles' argument that enables Tortoise to trigger an infinite regress?

On this analysis, the regress can arise because at each turn Tortoise demands that Achilles' presupposition be made explicit. By doing so, the presupposition becomes at issue and as such it is turned into a new premise. But as a new premise is added, arguing to the conclusion from the new set of premises requires a new presupposition. Tortoise demands that it too be made explicit and in this way turns it into a premise. Adding that premise alters the structure of the argument and triggers a new presupposition. And so on.

A little more formally, consider an argument such as ARGUMENT 1 and suppose one makes the presupposition that $Q$ follows from if $P_{1}, \ldots, P_{n}$ explicit in the form of a premise. The presupposition can be made explicit in one of two ways-either in the form of a conditional 'if $P_{1}, \ldots, P_{n}$ then $Q$ ' or in the form of a metasemantic claim ' $Q$ follows from $P_{1}, \ldots, P_{n}$ '. In both cases, the presupposition becomes a new premise $P_{n+1}$ (Fig. 2) and that will have the effect of altering the structure of ARGU- 


\begin{tabular}{|ccc|}
\hline ARGUMENT 1 & ARGUMENT 2 & ARGUMENT 3 \\
\hline$P_{1}$ & $P_{1}$ & $P_{1}$ \\
$\ldots$ & $\ldots$ & $\ldots$ \\
$P_{n}$ & $P_{n}$ & $P_{n}$ \\
$\left(Q\right.$ follows from $\left.P_{1} \ldots P_{n}\right) \rightarrow$ & $P_{n+1}$ & $P_{n+1}$ \\
& $\left(Q\right.$ follows from $\left.P_{1} \ldots P_{n+1}\right) \rightarrow$ & $\left(Q\right.$ follows from $\left.P_{1} \ldots P_{n+2}\right) \rightarrow$ \\
\hline
\end{tabular}

Fig. 2 The dynamic of the regress

MENT 1. A new piece of reasoning-ARGUMENT 2-comes about, one with a new presuppositional structure. Now suppose that one makes explicit the presupposition that $Q$ follows from $P_{1}, \ldots, P_{n}, P_{n+1}$ in ARGUMENT 2, so that it becomes a new premise $P_{n+2}$ A new piece of reasoning-ARGUMENT 3 - comes about. And so on (Fig. 2). ${ }^{18}$

\subsection{The unreasonability of tortoise}

Hence, the current proposal provides an explanatory account of how the infinite regress is triggered-by being licensed by the presuppositional structure of arguments, together with Tortoise's demand that the presuppositions be made explicit at each turn. A second explanandum is that, as many philosophers have observed, this demand of Tortoise's is plainly unreasonable (Wisdom 1974; Stroud 1979; Thompson 1980; Smiley 1995; Brandom 1994; Boghossian 2000; Broome 2013; Besson 2012; Engel et al. 2016). A diagnosis of the regress should explain what is unreasonable about this behavior.

Start by noticing that it is generally unreasonable to challenge or to request that something presupposed be made explicit, if it is common ground among all the participants of the conversation. For example, if it is commonly known that Mario has a sister, it would be irrational to reply to (23-a) with any of (23-b) and (23-c) (cf. (von Fintel, 2008, 2)):

a. My sister is arriving today.

b. You mean; if you have a sister, she is arriving today!

c. Wait a moment, do you have a sister?

\footnotetext{
18 According to Dynamic of the Regress (Fig. 2), if one makes the presupposition that $Q$ follows from $P_{1}, \ldots, P_{n}$ explicit in the form of a premise, so that it becomes a new premise $P_{n+1}$, that will have the effect of altering the structure of ARGUMENT 1. A new piece of reasoning-ARGUMENT 2-comes about, one with a new presuppositional structure. One might object: why think that ARGUMENT 2 must itself have its own non-stated presupposition? The reason for this is that 'therefore' comes with a deictic (or anaphoric) element (cf. Brasoveanu (2007, p. 296); Neta (2013, pp. 2009-2406)). Discourse deixis here is understood along the lines of Levinson (2004). If 'therefore' is a discourse deictic expression, then 'therefore' contains a deictic element whose reference changes in different linguistic contexts. So 'therefore' will pick up different sets of premises depending on the different linguistic contexts. By making explicit the presupposition in ARGUMENT 1, a new context is created and so new premises are fueled as antecedents for a novel application of 'therefore' in ARGUMENT 2. Because new premises are fueled, a new context is created and a new presupposition is triggered, different from $P_{n+1}$. Similarly, for ARGUMENT 3 , and so on.
} 
Now, in the exchange between Achilles and Tortoise, the very challenging of Achilles' presupposition by Tortoise and her demand that it be made explicit show that Achilles' presupposition was not part of the shared common ground between the Tortoise and Achilles. Hence, the unreasonability of her demand cannot be due to the fact that what is being challenged already belongs to the common ground.

However, something in the vicinity is plausible: speakers are entitled to expect that certain propositions that are particularly platitudinous be part of the common ground. For example, facts about the shared language of the participants to the conversation are plausibly among these platitudinous propositions-e.g., the proposition that the speaker is speaking, saying the words that one is saying are usually accessible to everybody present (cf. Stalnaker (1978, p. 323)). Plausibly among these propositions there are also propositions to the effect that certain entailment relations between sentences hold given the meaning of connectives and that certain patterns of entailment are valid. If so, they are among the propositions that speakers are entitled to expect to be, and to remain, part of the common ground. Challenging it and/or demanding that it be made explicit goes against this expectation. That is what makes it unreasonable. ${ }^{19}$

\section{Rule-following and revenge}

\subsection{Rule-following as a presupposition}

The presuppositional structure of arguments affords a response to the Structural Paradox that has the virtue of also explaining at what conditions the infinite regress is triggered and why Tortoise is being unreasonable. How does this response differ from and (if at all) improve on the standard rule-following account?

The current proposal differs from the many renditions of the rule-following account in both substance and precision. Proponents of the rule-following account often say that the modus ponens rule is 'implicit' in the practice of giving an argument by modus ponens (Brandom 1994; Broome 2000, 2006; Boghossian 2000), but they say little about what being implicit in a practice amounts to. On the present account, propositions, not rules, are implicit in arguments, for what is presupposed is a proposition-i.e., the proposition that the conclusion follows and that the rule is valid. The view also gives a precise statement of what it means for a rule to be 'implicit' in an argument: it is for the argument to presuppose that the rule and an instance of the rule hold - in a broadly Stalnakerian sense of presuppositions, one that we have independent reasons to think plays a central role in our linguistic practice.

This said, the proposal retains the key insights of the rule-following account. The idea that arguing by a rule is a matter of following a rule (Claim 2) is retained: on the current proposal, following a rule in the course of an argument is a matter of presupposing that the rule is valid. Also, the proposal affords an intuitive account of

19 There are instances of arguments of modus ponens whose validity is not platitudinous-e.g., McGee (1985)'s counterexamples to modus ponens. Note that the current diagnosis predicts that, in those cases, challenging the arguments in question is reasonable, precisely because in those cases it is not platitudinous that the conclusion follows from the premises, and hence, in those cases, speakers are not entitled to expect it to be part of the common ground that the conclusion follows from the premises. 
Claim 1 - that in a logical system, rules are to be distinguished from principles. The former are the logical relations that the logical system is allowed to presuppose that they hold; the latter are those logical relations instead that the system can express explicitly (in the object language, through explicit premises and object language connectives, or, in the metalanguage, through metasemantic clauses). Different logical systems differ in what they presuppose. A classical logical system differs from an intuitionistic logical system in that it takes it for granted that any sentence follows from its double negation; and it differs from a paraconsistent logical system in that it takes it for granted that anything follows from a contradiction.

\subsection{Presuppositions and revenge}

How does the current proposal overcome the revenge regress that threatens intentional construals of rule-following? As we have seen in Sect. 2, the revenge regress arises because on the intentional construal, following a rule requires being guided by the rule and, on the Application Model of guidance, applying a rule to a particular case requires making an inference of sort. In the case of argument by modus ponens, the Application Model would require that one appreciate that the rule of modus ponens is valid, that one check whether the premises $P$ and If $P$ then $Q$ fall under the rule, and that one then conclude that the rule licenses concluding to $Q$ in the particular case.

However, the current picture motivates thinking of being guided by the rule in a different, deflated sense, which does not fit the Application Model. As we have seen, presuppositions cannot be premises - in the technical sense of 'premises' introduced here-for they elude the scope of logical operators and so cannot be embedded by them or picked up by referential devices as premises can. Hence, plausibly presuppositions do not guide us in the same way premises do. Because the Application Model would involve turning presuppositions into premises, it cannot be the right model of how presuppositions guide us, if they do guide us at all.

I submit that presuppositions can guide us. This is true both of shared presuppositions and of private presuppositions. For example, common grounds guide the participants to a conversation to accepting certain assertions and to rejecting others (cf. Stalnaker 2002). Even private presuppositions might guide us, as when they dispose us to accept certain conclusions which we would not be disposed to accept had we not have made those presuppositions. But the way presuppositions guide us in accepting, e.g, $P$, is not by fueling us premises for inferences that have $P$-or accepting $P$-as a conclusion. For example, it is not as if participants to a conversation will accept Mary's assertion that John is in London upon realizing that the common ground supports the proposition that John is in London and thereby inferring that John is in London or that they ought to accept that John is in London. Rather, their sharing the common ground directly disposes them to accepting that proposition without having to undertaking a further inference.

So presuppositions do guide us but not in the way premises do-by directly (noninferentially) disposing us rather than by fueling us premises for further inferences. In epistemology, this distinction between difference kinds of guidances (or bases) is independently motivated. Consider the way perception guides our belief-formation. 
My perceptually seeing a dog outside disposes me to forming a belief that there is, without necessarily constituting a premise in an argument for that belief. If so, it is an implicit, rather than an explicit, basis. To capture the way perceptual evidence can base our beliefs, Williamson (1997, p. 729) similarly distinguishes between explicit bases and implicit bases. ${ }^{20}$ An explicit basis is a premise belief from which we infer another belief. Implicit bases, instead, do not need to be premises. Like perceptual states, they guide one directly, not by fueling premises for further inferences. Presuppositions are implicit, rather than explicit, bases. In this sense, when, given certain premises that have the form $P$ and if $P$ then $Q$, the presupposition that the rule of modus ponens is valid guides one by directly disposing one to accepting the conclusion of the form $Q$, without further inference, just like a common ground directly disposes participants to a conversation to jointly accepting a certain assertion, without further inference.

\subsection{Presuppositions and contextual salience}

While the Application Model assumes that knowledge of validities can guide us - and hence can be applied to a particular case-only through further inference, according to the present response to the revenge regress, knowledge of validities can guide us directly as presuppositions do. These two different ways in which a rule can guide us - as a premise or as a presupposition — can also be illustrated with the logical distinction between universal instantiation and substitution (cf. Besson (2019), Section 2.1). On the Application Model, we can come to see that a logical principle applies in a particular case by going through an argument by universal instantiation from the logical principle taken as a general premise (to the effect, say, that for every $P$ and $Q$, if $P$ and if $P$ then $Q$, then $Q$ follows) to the conclusion that the relevant instance of that general principle holds. This application requires an argument and so generates the revenge regress. But being a premise of an argument by universal instantiation is not the only way in which a logical principle can guide us in a particular case. Another way for, e.g., modus ponens to guide us is for it to license certain substitution instances - e.g., to license the substitution instances of the form $Q$ from premises of the form $P$ and if $P$ then $Q$. As Besson (2019) puts it, logicians tend not to think of substitution as an inferential step. Rather, they think of it as a non-inferential transition governed by meta-principles of that logical system. By performing substitution (rather than universally instantiating), we manifest the ability to recognize directly (i.e., noninferentially) certain patterns of arguments as contextually salient and in this way to recognize directly certain instances of those patterns as valid.

So, our knowledge of validities can guide us as an implicit basis/presupposition rather than as an explicit basis/premise and this difference in modes of guidance is illustrated by the logical distinction between universal instantiation and substitution and by the corresponding competences. On this proposal, rule-following dispositions involve a non-inferential competence of recognizing certain patterns of arguments as contextually salient and so of coming to directly (i.e., non-inferentially) see certain

\footnotetext{
20 According to Williamson (1997), 'explicit evidence bases' are not just beliefs but evidential/knowledge states. This aspect of Williamson's distinction is not relevant here.
} 


\begin{tabular}{|c|c|c|}
\hline & Premise & Presupposition \\
\hline Linguistic distinction & Scope in/d-challengeable & Scope out/not d-challengeable \\
\hline Epistemic distinction & Explicit basis & Implicit basis \\
\hline Logical distinction & Universal Instantiation & Substitution \\
\hline Psychological distinction & Inferential competence & non-inferential competence \\
\hline
\end{tabular}

Fig. 3 Premises versus presuppositions

instances as valid and these rule-following dispositions are explained at least in part in terms of knowledge of validities.

Figure 3 summarizes the different (linguistic, epistemic, logical, psychological) dimensions along which presuppositions differ from premises: in their not being directly challengeable and scoping out of connectives, in their being implicit rather than explicit bases, in licensing substitution rather than having to be applied through universal instantiation, and in grounding a direct and non-inferential competence.

Why think that knowledge of validities can at least in part explain these rulefollowing dispositions? Compare knowledge of validities to other cases where knowledge about a domain seems to at least partly ground a similar sort of noninferential cognitive competence. Consider how a chess player's knowledge of chess-including their knowledge of the rules and of the possible configurations on the chessboard-can guide them in directly seeing what possibilities are afforded by the current chessboard: in virtue of their knowledge, a chess player can simply call to mind the possibilities afforded by a configuration of pieces on the chessboard, without needing to derive them inferentially from the rules of chess or from their mental catalog of possible configurations. To be sure, knowledge of chess is not sufficient for recognizing the possibilities afforded by a configuration of pieces on the boardone in addition needs practice and experience in developing the relevant recognitional abilities (as well as all-purpose abilities such as perceptual and attentional abilities). Nonetheless, their knowledge about chess at least partly explains such an ability. ${ }^{21}$ Similarly, the knowledge of validities (in a language) that we gain by virtue of being competent speakers (of that language) by itself might not be sufficient to entirely ground a non-inferential competence of recognizing certain patterns of arguments as contextually salient. So, one might presuppose that a certain rule is valid but not having exercised it enough, one might not have developed the ability to directly recognize a particular argument as instantiating the relevant pattern. In this case, one might fail to accept an argument by modus ponens, despite presupposing the validity of the rule. Like virtually for any skillful performance, training, experience, and all-purpose abilities (like the ability to recognize alike patterns) are needed in addition to knowledge. But this is compatible with the relevant cognitive competence, and the relevant

21 (Cf. Valaris 2017 pp. 2017-2018) who discusses a semantic model, inspired by Johnson-Laird (1983)'s mental model approach, on which understanding an argument involves creating a model for the premises with respect to which the conclusion is assessed. On this semantic model, competent speakers of English come to directly see that the conclusion follows, upon understanding the premises and the meaning of the conclusion, without having to undertake an inference that has as its premise that the relevant rule is valid. In the main text, I remain neutral on the details of the psychological mechanisms underlying our understanding and acceptance of arguments. 
rule-following dispositions, being nonetheless at least partly grounded on the relevant knowledge.

\subsection{Presuppositions versus mere dispositions}

The presuppositional account of rule-following differs from the merely dispositional construal in that it takes one's rule-following dispositions to be at least partly grounded on an attitude of the rule-follower-i.e., on their presupposing that the relevant rule is valid. As we have seen (Sect. 2.3), some have already pointed out that the explanatoriness of the merely dispositional account is questionable (Boghossian (2014, p. 14); Fodor 2008). Let me highlight some explanatory advantages of the presuppositional account over the merely dispositional account.

Rule-following attributions come with certain normative consequences. So for example, from the fact (a) that one follows the rule of modus ponens and (b) that one follows the classical rules for negation, a further normative claim follows-i.e., (C) one also should follow the rule of modus tollens. On the merely dispositional account, however, it is rather mysterious how normative consequences like (C) come about. For example, from the fact that one is merely disposed to accept modus ponens arguments and from the fact that one is merely disposed to accept arguments by the classical rules of negation - where these dispositions are not themselves grounded on a commitment to the validity of the rules, nor on an attitude that has those rules as its content-it does not thereby follow that one ought to also be disposed to accept arguments by modus tollens. Bare dispositions simply do not elicit this sort of normative commitments. By contrast, attitudes $d o$ elicit this sort of normative commitments (whether they are tacit or not): from the fact that e.g., one (tacitly or non-tacitly) has certain beliefs, certain things follow about what else one ought to (tacitly or non-tacitly) believe. On the current proposal, one's rule-following dispositions are grounded on a (possibly tacit) attitude towards the validity of the relevant rule. And it is clear that if one is committed to modus ponens, by presupposing that it is valid, and is also committed to the classical rules for negation, by presupposing that those rules are valid, one ought to also be committed to the rule of modus tollens-i.e., one would also have to presuppose that the rule of modus tollens is valid.

So the presuppositional account of rule-following improves on the merely dispositional account in that it can account for the distinctive normative commitments elicited from rule-following attributions. To the extent that these normative commitments are ones that proponents of the rule-following account would want to explain, the presuppositional account provides a better theory of rule-following that the merely dispositional account.

\section{Objections}

By studying the presuppositional structure of arguments, we have found an independently motivated model of how to think of guidance by a rule in a course of an argument that differs from the Application Model. Because the revenge regress only arose on 
Application Model of guidance, the current proposal avoids the revenge regress. In this section, I discuss two objections to the current proposal.

The first is that the focus on 'therefore' results in my response to the Structural Paradox to be too limited, for 'therefore' privileges arguments with categorical premises, whereas the regress can arise also in the context of arguments with suppositional premises. The second is that, if arguments are constitutively presuppositional, then my response has the implausible consequence that every argument is questionbegging and uninformative. Let me consider them in turn.

\subsection{The regress in subarguments}

As Pavese (2017) has observed, 'therefore' is not always allowed in the context of a supposition: ${ }^{22}$
a. It is raining. Therefore/so/hence, the streets are wet.
b. ??Suppose it is raining; therefore/so/hence the streets are wet.
c. ??If it is raining, therefore/so/hence the streets are wet.

If 'therefore' could only occur in arguments with categorical premises, the present analysis might seem to predict that the regress could only arise in arguments with categorical premises. That would be a bad prediction, because of course the regress can also arise within subarguments. ${ }^{23}$

Luckily, the data is more complex and should be assessed with caution. 'Therefore' can be licensed in the context of a supposition, when the linguistic environment is subjunctive:

(25) a. Suppose it were raining. The streets would, therefore, be wet.

b. If it were raining, the streets would, therefore, be wet.

c. If Mary were English, she would, therefore, be brave.

d. Suppose Mark were Englishman. He would, therefore, be brave.

Moreover, 'therefore' is tolerated with so-called 'advertising conditionals' - interrogatives that play a role in discourse similar to that of antecedents of conditionals:

Single? (Then) You have not visited Match.com. (Starr $(2014,4)$ )

a. Single? Therefore, you have not visited Match.com.

b. Still looking for a good pizzeria? Therefore you have not tried Franco's yet.

This suggests that at least under certain conditions, 'therefore' can appear in suppositional contexts. This data is congenial to the idea that premises of an argument can

${ }^{22}$ Under supposition, connectives like 'then' are much preferred to 'therefore':

(i) a. Suppose it is raining. Then, the streets are wet.

b. If it is raining, then the streets are wet.

23 I am thankful to Tim Williamson for forcefully raising this objection to me. 
be supposed as well as asserted. If so, then pace (Pavese 2017), the current theory of argument modeled along a semantics for 'therefore' can predict that, just like categorical arguments, subarguments also have a presuppositional structure and, as such, are susceptible to Lewis Carroll's regress.

\subsection{Begging the question and accommodation}

On this current proposal, in virtue of presupposing something more general, every argument with the form of Argument Schema will take for granted that $C$ follows from $P_{1}, \ldots, P_{n}$ :

Argument Schema $P_{1}, \ldots, P_{n}$. Therefore $C$.

But is not the whole point of an argument of this form to establish that something follows from its premises? If so, how can that be a presupposition, rather than the point, of the argument?

The crucial idea, which the current semantic analysis motivates, is that the main point of an argument is not that of asserting that something follows from the premises. That is exactly what Grice's not-at-issue tests, Pavese's projection tests, as well as the other tests considered in Sect. 3 establish. Rather, an argument of that form aims at reaching the conclusion, upon asserting or supposing its premises, and it accomplishes that by taking certain things for granted.

Does not this proposal make arguments of this form question-begging, though? On the technical definition of a question-begging argument, an argument is questionbegging only if it presupposes the truth of its conclusion (Hoffman 1971; Sanford 1972). So, technically, the proposal does not render all arguments question-begging, because according to it, making an argument from $P_{1}, \ldots, P_{n}$ to $C$ does not require presupposing that $C$ is true; rather, it only requires presupposing that $C$ follows from $P_{1}, \ldots, P_{n} .^{24}$

Now, it is true that the current proposal does predict that certain arguments are circular. For example, in Argument B, the proposition that $Q$ follows from $P$ and if $P$ then $Q$ is indeed presupposed by its subargument:
Argument B
$\mathrm{P}$, if $\mathrm{P}$ then $\mathrm{Q}_{i}$
Therefore $_{i}$, Q
Therefore $_{j}$, if $\mathrm{P}$ and if $\mathrm{P}$ then $\mathrm{Q}, \mathrm{Q}$ follows.

But intuitively, Argument B is circular. Hence, this is the correct prediction.

A related worry is that, if every argument presupposes that its premises entail the conclusion, then no argument can be really informative, for there is a sense in which its conclusion will be already 'contained' in the premises. In response, start by noticing that the current proposal delivers that in many cases making a complex argument can be informative. For example, consider Argument C:

\footnotetext{
${ }^{24}$ It is worth noting that this important distinction between presupposing that $\mathrm{C}$ is true and presupposing that $\mathrm{C}$ follows from $P_{1}, \ldots, P_{n}$ cannot be easily modeled on the standard coarse-grained model of common ground. But this limitation is limitation of that model of common ground and should not be taken to indicate that the distinction is not there.
} 
Argument C John is in London ${ }_{i}$. Therefore ${ }_{i}$, he is in the UK. Therefore ${ }_{i}$, he is in Europe. Therefore ${ }_{i}$, he is not in Asia.

Argument C concludes to John's not being in Asia from he is being in London, and at no point in the argument was the proposition that his not being in Asia follows from John's being in London presupposed by the argument. In this sort of case, the proposal correctly predicts that new knowledge can be acquired by means of an argument.

Secondly, even simple arguments can be informative, for presuppositions can sometimes be informative-i.e., they can result in a restriction of the context set, through the phenomenon of accommodation (Lewis (1979, p. 340); von Fintel 2008). For example, suppose it is not known in the context that Pittsburgh is in Pennsylvania. The presupposition triggered by Argument D is most likely to be accommodated in this context and this accommodation will result in restricting the context set-by ruling out possibilities where Pittsburgh is located in a state other than Pennsylvania:

Argument D John is in Pittsburgh. Therefore, he is in Pennsylvania.

Finally, does not the current proposal predict that there is no possibility of knowledge-extension for one-step arguments? For example, one might worry that Argument E cannot be knowledge extending, if it presupposes that the conclusion follows from its premises:

Argument E P, if P then Q, Therefore, Q.

However, as discussions of the problem of deduction teach us, an argument can be uninformative and yet be knowledge-extending. The problem of deduction is the problem of how any logically valid argument can ever be knowledge-extending ( Mill 1846), given that its conclusion is contained in the premises and in the structure of the argument. According to a prominent response, an argument can generate new knowledge, despite being uninformative, because reaching a conclusion from certain premises might extend our knowledge by making us form an epistemically supported belief in the conclusion which we did not previously have (cf. Rumfitt 2008).

In conclusion: while the current proposal correctly predicts that arguments like Argument B are circular, it does not predict that arguments in general are. Moreover, it is compatible with arguments being informative and knowledge-extending - such as Argument C or those, like Argument D, that require accommodation. Finally, one-step arguments such as Argument E can be uninformative and yet knowledgeextending, in accordance with a popular solution to the problem of deduction.

\section{Conclusions}

According to the response to the Structural Paradox developed in this essay, Lewis Carroll's paradox teaches us something foundational about the nature of arguments. What it teaches us is that the task of making everything explicit in arguments is doomed to be endless, for as argument-givers, we constitutively take things for granted: arguments are possible only against a non-empty set of presuppositions. 
The idea that arguments are constitutively presuppositional is not at all novel. Just to name two famous examples, Wittgenstein (1969) argues that testing is constitutionally presuppositional and so are inferences that are involved in scientific practice. Wright (2004b) (cf. also Wright 2004a) argues for the presuppositional nature of arguments starting from considerations having to do with Moore's paradox and skepticism. The novelty of the argument developed in this essay relies on how this conclusion is reached - as a response to the Structural Paradox that is independently motivated by a study of how we argue.

In Sect. 2, we discussed the common diagnosis, endorsed by Russell and others. As we have seen, Russell thought that Lewis Carroll's regress motivated a distinction between two types of relations: the relation of an antecedent to consequent (and is expressed by 'if then') and the relation that holds between premises and conclusions in an argument - the latter relation being metalogical because it cannot be expressed in formal systems without regress. The current proposal vindicates this thought underlying Russell's endorsement of the common diagnosis. For the current proposal also takes the regress to show that the relation between premises and conclusion in an argument cannot be required to be explicitly expressed to hold in first-order arguments, on pain of regress. However, on this proposal, this relation is metalogical, in the sense that it can be explicitly expressed to hold in the metatheory when one gives the soundness and completeness proofs.

According to the response to the Structural Paradox developed here, giving an argument by a rule is possible by following that rule; and following a rule in the course of an argument is a matter of presupposing that certain entailment relations hold. Because it grounds rule-following dispositions in attitudes of the rule-follower towards the validity of the relevant rules, the presuppositional account of rule-following is better suited than the merely dispositional accounts to explaining the distinctive normative commitments that are elicited by rule-following. Finally, the presuppositional view of rule-following overcomes the revenge regress that afflicts other intentional construals of rule-following by motivating a way of thinking of guidance by a rule alternative to the Application Model.

This proposal echoes some remarks by Broome (2013, pp. 230-234) who talks as if when arguing, e.g., from it is raining and from if it is raining, the street will be wet, to the conclusion that the streets are wet, we background a 'linking' belief about the conclusion following from the premises. ${ }^{25}$ While Broome thinks that the presence of a linking backgrounded belief is plausible, he worries that the relevant background belief will not be part of an argument, because, on pain of Carroll's regress, linking beliefs cannot be extra premises. The picture developed in this essay speaks to this concern. The semantics and pragmatics of arguments independently motivates taking the structure of arguments to be presuppositional. Hence, this picture motivates and explains how something backgrounded can be part of an argument without being a premise-i.e., by being a presupposition of the argument.

According to this proposal (see Sect. 4), that a certain rule is valid in one's language is among the semantic conventions that one presupposes when speaking that language. This claim does not thereby commit one to inferentialism about the meaning of logical

25 See also Besson (2012). 
connectives (e.g., Peacocke 1987; Boghossian 1996; Brandom 1994; Tennant 2002). Indeed, the current view does not take a stance on whether the meaning of logical connectives is fully determined by their rules (as inferentialism has it) ${ }^{26}$ or, rather, the converse is true-i.e., certain rules are valid in virtue of the meaning of the relevant logical connectives. Although the view is also compatible with conventionalism about logic - the view that logical truths and logical validities are fully explained by linguistic conventions (e.g., Warren (2020), p. 10) - it does not entail it. For one might endorse the view advanced here while at the same time take the validity of logical rules to be only partly a matter of linguistic convention-and partly to depend on other facts, such as how our mind works or how reality is fundamentally structured.

This essay has not tried to discuss the Cognitive Paradox. However, this response to the Structural Paradox promises to cast light on the Cognitive Paradox too. Cognitive scientists routinely explain cognitive systems' behavior in terms of their presupposing certain things-e.g., that the visual system presupposes that the light comes from above or that there is only one light source Ramachandran (Ramachandran (1988), p. 76), Scholl (2005). Moreover, we do ordinarily assign a role to presuppositions in reasoning, when we explain one's reaching a certain conclusion by appealing to the fact that they were taking certain truths for granted. The success of these explanatory practices suggests that presuppositions might play a central role not just in our linguistic practice but also in our cognitive lives.

Although I stayed away from embracing any cognitive proposal, my account is motivated by a study of the semantics and pragmatics of arguments. Methodologically, this endeavor is similar to that of modeling rational communication-communication for beings that share many features of our rationality but not necessarily our psychologystarting from a semantics for natural languages (e.g., Lewis 1969, 1979; Stalnaker 1987; Soames 2008). The thought is that just like the general structure of rational communication can be extracted from a study of our ordinary linguistic practice, in a similar way, the general structure of rational arguments can be extracted from a study of our ordinary argumentative practice. This sort of approach is particularly congenial when it comes to addressing the Structural Paradox, for this paradox does arise from the consideration that, despite the possibility of the regress, we do routinely give arguments by modus ponens. For this reason, it is not surprising that looking at how we ordinarily argue can provide a fruitful avenue for explaining how that can be.

\section{Compliance with ethical standards}

Conflict of interest The authors declare that they have no conflict of interest.

Ethical approval This article does not contain any studies with human participants performed by any of the authors.

Informed consent This article does not contain any studies with human participants or animals performed by any of the authors.

26 At least according to a rather standard characterization of inferentialism. Cf. Warren (2020), p. 58. 


\section{References}

Abrusán, M. (2016). Presupposition cancellation: Explaining the 'soft-hard' trigger distinction. Natural Language Semantics, 24(2), 165-202.

Abusch, D. (2010). Presupposition triggering from alternatives. Journal of Semantics, 27(1), 37-80.

Asher, N. (1993). Reference to abstract entities. Dordrecht: Kluwer Academic Publishers.

Asher, N., Asher, N. M., \& Lascarides, A. (2003). Logics of conversation. Cambridge: Cambridge University Press.

Audi, R. (1986). Belief, reason, and inference. Philosophical Topics, 14(1), 27-65.

Bach, K. (1999). The myth of conventional implicature. Linguistics and Philosophy, 22(4), 327-366.

Bach, K. (2006). The top 10 misconceptions about implicature. In Drawing the boundaries of meaning: Neo-Gricean studies in pragmatics and semantics in honor of Laurence R. Horn (pp. 21-30).

Beaver, D. I. (2001). Presupposition and assertion in dynamic semantics (Vol. 29). Stanford: CSLI publications Stanford.

Beaver, D. I., \& Geurts, B. (2014). Presupposition. In Zalta, E. N., editor, The Stanford Encyclopedia of Philosophy. Metaphysics Research Lab, Stanford University, winter 2014 edition.

Besson, C. (2012). Logical knowledge, and ordinary reasoning. Philosophical Studies, 158(1), 59-82.

Besson, C. (2018). Norms, reasons and reasoning: A guide through Lewis Carroll regress argument. In D. Star (Ed.), The Oxford handbook of reasons and normativity. Oxford: Oxford University.

Besson, C. (2019). Knowledge of logical generality and the possibility of deductive reasoning. In Inference and consciousness (pp. 172-196). Routledge.

Boghossian, P. (2000). Knowledge of logic. New Essays on the a Priori, 22, 9254.

Boghossian, P. (2003). Blind reasoning. Aristotelian Society Supplementary, 77(1), 51.

Boghossian, P. (2014). What is inference? Philosophical Studies, 169(1), 1-18.

Boghossian, P. A. (1996). Analyticity reconsidered. Noûs, 30(3), 360-391.

Brandom, R. (1994). Making it explicit. Cambridge: Harvard University Press.

Bras, M., Le Draoulec, A., \& Asher, N. (2009). A formal analysis of the french temporal connective alors. Oslo Studies in Language, 1(1), 921.

Bras, M., Le Draoulec, A., \& Vieu, L. (2001). French adverbial puis between temporal structure and discourse structure. Semantic and pragmatic issues in discourse and dialogue: Experimenting with current theories, CRiSPI series, 9, 109-146.

Brasoveanu, A. (2007). Structured nominal and modal reference. Ph.D. thesis, Rutgers University New Brunswick, NJ.

Broome, J. (2000). Normative requirements (pp. 79-99). Oxford: Blackwell Publishers.

Broome, J. (2006). Reasoning with preferences? Royal Institute of Philosophy Supplements, 59, 183-208.

Broome, J. (2013). Rationality through reasoning. Hoboken: Wiley.

Broome, J. (2014). Comments on Boghossian. Philosophical Studies, 169(1), 19-25.

Brown, D. (1954). What the Tortoise taught us. Mind, 63(250), 170-179.

Carroll, L. (1895). What the Tortoise said to Achilles. Mind, 4(14), 278-80.

Davis, W. (2014). Implicature. In Zalta, E. N., (Ed.) The Stanford encyclopedia of philosophy. Metaphysics Research Lab, Stanford University, fall 2014 edition.

Dennett, D. (2002). Content and consciousness. New York: Routledge.

Dogramaci, S. (2010). Knowledge of validity. Noûs, 44(3), 403-432.

Dummett, M. A. (1973). The justification of deduction. London: Oxford University Press.

Engel, P., Abeles, F., \& Moktefi, A. (2016). The philosophical significance of Carroll's regress. 'What the Tortoise Said to Achilles' Lewis Carroll's Paradox of inference, the Carrollian (p. 28).

Fodor, J. A. (2008). LOT 2: The language of thought revisited: The language of thought revisited. Oxford: OUP Oxford.

Fumerton, R. A. (1995). Metaepistemology and skepticism. New York: Rowman and Littlefield Publishers. Geach, P. T. (1965). Assertion. The Philosophical Review, 25, 449-465.

Grice, H. P. (1975). Logic and conversation. In P. Cole \& J. Morgan (Eds.), Syntax and semantics (Vol. 3, pp. 43-58). New York: Academic Press.

Groenendijk, J. A. G., \& Stokhof, M. J. B. (1984). Studies on the semantics of questions and the pragmatics of answers. Ph.D. thesis, University of Amsterdam.

Gupta, A. (2006). Empiricism and experience. Oxford: Oxford University Press.

Hamblin, C. L. (1970). Fallacies. London: Methuen. 
Heim, I. (1983). On the projection problem for presuppositions. Formal Semantics-The Essential Readings, $36,249-260$.

Hlobil, U. (2014). Against Boghossian, Wright, and Broome on inference. Philosophical Studies, 167(2), 419-429.

Hoffman, R. (1971). On begging the question at any time. Analysis, 32(2), 51-51.

Horn, L. R. (1985). Metalinguistic negation and pragmatic ambiguity. Language, 61(1), 121-174.

Johnson-Laird, P. N. (1983). Mental models: Towards a cognitive science of language, inference, and consciousness (Vol. 6). Harvard: Harvard University Press.

Karttunen, L. (1973). Presuppositions of compound sentences. Linguistic inquiry, 4(2), 169-193.

Karttunen, L. (1974). Presupposition and linguistic context. Theoretical Linguistics, 1, 181-94.

Karttunen, L., \& Peters, S. (1979). Conventional implicature. In Presupposition (pp. 1-56). Brill.

King, J. C., et al. (2007). The nature and structure of content. Oxford: Oxford University Press.

Kocurek, A., \& Pavese, C. (2020). The dynamics of argumentative discourse. Manuscript.

Kripke, S. A. (1982). Wittgenstein on rules and private language: An elementary exposition. Harvard: Harvard University Press.

Levinson, S. C. (2004). Deixis. The handbook of pragmatics, (p. 97).

Lewis, D. (1969). Conventions: A philosophical study. Cambridge: Harvard University Press.

Lewis, D. (1979). Scorekeeping in a language game. Philosophical Papers, 1, 233-49.

Longino, H. E. (1978). Inferring. Philosophy Research Archives, 4, 17-26.

MacFarlane, J. (2004). In what sense (if any) is logic normative for thought. Unpublished manuscript.

Mandelkern, M. (2016). Dissatisfaction theory. Semantics and Linguistic Theory, 26, 391-416.

McGee, V. (1985). A counterexample to modus ponens. The Journal of Philosophy, 82(9), 462-471.

Mill, J. S. (1846). A system of logic, ratiocinative and inductive, book iii. Harpers., 3, 8.

Murray, S. E., \& Starr, W. B. (2020). The structure of communicative acts. Linguistics and Philosophy, 53, $1-50$.

Neta, R. (2013). What is an inference? Philosophical Issues, 23(1), 388-407.

Padro, R. (2015). What the Tortoise said to Kripke: The adoption problem and the epistemology of logic. CUNY, Ph.D. Dissertation.

Parsons, T. (1996). What is an argument? The Journal of Philosophy, 93(4), 164-185.

Pavese, C. (2017). On the meaning of "therefore". Analysis, 77(1), 88-97.

Pavese, C. (2020). Reasoning and presuppositions. Manuscript.

Pavese, C. (2021). The semantics and pragmatics of argumentation. In D. Altshuler (Ed.), Linguistics meets philosophy. Cambridge: Cambridge University Press.

Peacocke, C. (1987). Understanding logical constants: A realist's account. Proceedings of the British Academy, 73, 153-199.

Pearson, H. (2010). A Modification of the 'hey, wait a minute' test. Snippets, 1, 82.

Peirce, C. S. (1974). Collected papers of Charles Sanders peirce (Vol. 5). Harvard: Harvard University Press.

Philie, P. (2007). Carroll's regress and the epistemology of logic. Philosophical Studies, 134(2), 183-210.

Portner, P. (2004). The semantics of imperatives within a theory of clause types. Semantics and Linguistic Theory, 14, 235-252.

Portner, P. (2007). Imperatives and modals. Natural Language Semantics, 15(4), 351-383.

Portner, P. (2016). Imperatives. In M. Aloni \& P. Dekker (Eds.), Cambridge handbook of semantics. Cambridge: Cambridge University Press.

Potts, C. (2007). Into the conventional-implicature dimension. Philosophy compass, 2(4), 665-679.

Potts, C. (2015). Presupposition and implicature. The Handbook of Contemporary Semantic Theory, 2 , 168-202.

Potts, C., et al. (2005). The logic of conventional implicatures (Vol. 7). Oxford: Oxford University Press.

Ramachandran, V. S. (1988). Perception of shape from shading. Nature, 331(6152), 163-166.

Roberts, C. (2018). Speech acts in discourse context. In New Work on Speech Acts (p. 317).

Rothschild, D. (2011). Explaining presupposition projection with dynamic semantics. Semantics and Pragmatics, 4, 3-1.

Rumfitt, I. (2008). Knowledge by deduction. Grazer Philosophische Studien, 77(1), 61-84.

Rumfitt, I. (2011). Inference, deduction, and logic. In J. Bengson \& M. Moffett (Eds.), Knowing how: Essays on knowledge, mind, and action (pp. 334-350). Oxford: Oxford University Press.

Russell, B. (1903). The principles of mathematics. Cambridge: Cambridge University Press. 
Ryle, G. (1945). Knowing how and knowing that: The presidential address. Proceedings of the Aristotelian Society, New Series, 46, 1-16.

Sanford, D. H. (1972). Begging the question. Analysis, 32(6), 197-199.

Schlenker, P. (2009). Local contexts. Semantics and pragmatics, 2, 1-3.

Schlenker, P. (2010). Local contexts and local meanings. Philosophical Studies, 151(1), 115-142.

Scholl, B. J. (2005). Innateness and (Bayesian) visual perception (p. 34). The innate mind: Structure and contents.

Smiley, T. (1995). A Tale of Two Tortoises. Mind, 104(416), 725-736.

Soames, S. (2008). Drawing the line between meaning and implicature, and relating both to assertion. Nous, $42(3), 440-465$.

Stalnaker, R. (1975). Indicative conditionals. In Language in focus: Foundations, methods and systems (Vol. 43, pp. 179-196), The series Boston Studies in the Philosophy of Science. Springer.

Stalnaker, R. (1977). Pragmatic presuppositions. In Proceedings of the Texas conference on performatives, presuppositions, and implicatures (pp. 135-148). Arlington, VA: Center for Applied Linguistics, ERIC.

Stalnaker, R. (1987). Inquiry. Cambridge: MIT Press.

Stalnaker, R. (2002). Common ground. Linguistics and Philosophy, 25(5/6), 701-721.

Stalnaker, R. C. (1978). Assertion (pp. 147-161). Formal Semantics: The Essential Readings.

Starr, W. B. (2014). What 'If'? Philosophers' Imprint, 14(10), 68.

Starr, W. B. (2020). A preference semantics for imperatives. Semantics and Pragmatics 13, 6.

Stroud, B. (1979). Inference, belief, and understanding. Mind, 88(1), 179-196.

Tennant, N. (2002). The taming of the true. Oxford: Oxford University Press.

Thompson, J. (1980). Reasons and reasoning. In M. Black (Ed.), Philosophy in America (pp. 298-314). Ithaca: Cornell University Press.

Tonhauser, J., Beaver, D., Roberts, C., \& Simons, M. (2013). Toward a taxonomy of projective content. Language, 21, 66-109.

Valaris, M. (2017). What reasoning might be. Synthese, 194(6), 2007-2024.

Veltman, F. (1996). Defaults in update semantics. Journal of Philosophical Logic, 25(3), 221-261.

Von Fintel, K. (2004). Would you believe it? The King of France is back! Presuppositions and truth-value intuitions. In Reimer, B. (Ed.) Descriptions and beyond (pp. 315-42).

von Fintel, K. (2008). What is presupposition accommodation, again? Philosophical Perspectives, 22, 137170.

von Fintel, K., \& Gillies, A. (2007). An opinionated guide to epistemic modality. Oxford studies in Epistemology, 2, 32-62.

Walton, D. N. (1990). What is reasoning? What is an argument? The Journal of Philosophy, 87(8), 399-419.

Warren, J. (2020). Shadows of syntax: Revitalizing logical and mathematical conventionalism. Oxford: Oxford University Press.

Willer, M. (2013). Dynamics of epistemic modality. Philosophical Review, 122(1), 45-92.

Williamson, T. (1997). Knowledge as evidence. Mind, 106(424), 717-741.

Winch, P. (1958). The idea of a social science and its relation to philosophy. London: Routledge.

Wisdom, W. A. (1974). Lewis Carroll's infinite regress. Mind, 25, 571-573.

Wittgenstein, L. (1953). Philosophical Investigations: The English Text of the (3rd ed.). Macmillan: London. Wittgenstein, L. (1969). On certainty (Vol. 174). Oxford: Blackwell.

Wright, C. (2004a). Intuition, entitlement and the epistemology of logical laws. Dialectica, 58(1), $155-175$.

Wright, C. (2004b). Scepticism, certainty, Moore and Wittgenstein. In Wittgenstein's lasting significance (pp. 241-261). Routledge.

Wright, C. (2014). Comment on Paul Boghossian, "What is inference?". Philosophical Studies, 169(1), 27-37.

Publisher's Note Springer Nature remains neutral with regard to jurisdictional claims in published maps and institutional affiliations. 